\title{
Perfil e comportamento do consumidor de bromélias: orientação a produção rural
}

\section{Adilson Anacleto}

adilson.anacleto@unespar.edu.br

Universidade Estatual do Paraná, Brasil

Ana Paula de Araujo Bornancin Anna bornancin@hotmail.com

Universidade Estatual do Paraná, Brasil

\begin{abstract}
RESUMO
As bromélias no litoral do Paraná, tem a sua exploração comercial associada as comunidades socialmente vulneráveis, porém, pouco se sabe sobre os desejos dos consumidores, neste contexto, apresenta-se o resultado da avaliação sobre a influência do composto de marketing no comportamento do consumidor de bromélias, visando subsidiar o estabelecimento de ações no campo para o fortalecimento da cadeia produtiva. Para que os objetivos fossem alcançados, foi realizada pesquisa exploratóriadescritiva, entre julho de 2016 e fevereiro de 2017, junto a 150 consumidores de bromélias. Identificou-se o gênero feminino como consumidor majoritário $(n=80)$, que efetuavam em média 3,62 compras por ano, com tendência a elevação no consumo, a medida que avançavam a escolaridade e renda. O estudo mostrou ainda, que apesar do consumidor estar satisfeito com as bromélias como plantas ornamentais a expectativa não é atendida especialmente em relação ao preço classificado como elevado. Conclui-se que devem ser reavaliadas as formas de produção no campo, o número de espécies priorizando as mais desejadas pelos clientes. A orientação dos varejistas aos produtores pode criar um ambiente colaborativo, ampliando a eficiência da produção no campo, e dos níveis de satisfação do consumo, fortalecendo a cadeia produtiva de bromélias no litoral do Paraná.
\end{abstract}

PALAVRAS-CHAVE: Comércio de flores, agronegócio, plantas ornamentais, floricultura, litoral do Paraná. 


\section{INTRODUÇÃO}

O comércio de flores e plantas ornamentais em geral no Brasil vem crescendo em média $8 \%$ ao ano, sendo que este crescimento é fortemente estimulado por 28 distribuidores atacadistas, e também por mais de 18 mil pontos de vendas diretos ao consumidor como floriculturas, garden centers, supermercados entre outros que juntos são responsáveis pelo comércio de $96,5 \%$ da produção brasileira (JUNQUEIRA E PEETZ, 2014; MURARO et al., 2016).

Apesar do comercio de flores no Brasil ser muito dependente de datas sazonais como finados, dia das mães, dia internacional da mulher e dia dos namorados, o comercio de flores movimentou $\mathrm{R} \$ 5,64$ bilhões no ano anterior (SEBRAE, 2015).

A produção e comércio de flores no Brasil, é segmentada, e as flores tropicais, têm apresentado taxas de crescimento de produção e comércio, ainda maior quando comparado com as outras espécies tradicionais, portanto boas expectativas de mercado. Fortemente impulsionadas pela coloração e folhagem exótica, este grupo de plantas tem ganhado adeptos dentro e fora do Brasil (NEGRELLE et al., 2012; ANACLETO et al., 2015).

Apesar da tendência de crescimento do comércio das flores tropicais, as bromélias que fazem parte desta segmentação de mercado, não tem apresentado a mesma tendência, ainda que Anacleto et al. (2014) descrevam que $90,5 \%$, dos consumidores de flores em geral possuem apreço por essa planta ornamental.

As bromélias são plantas monocotiledôneas da família Bromeliaceae, nativa das Américas. Atualmente estão catalogados 50 gêneros e número superior a 3000 espécies. Esta planta recebe nomes variados no Brasil, porém entre os mais conhecidos são gravatá, caraguatá e bromélia (ANACLETO, et al., 2008).

O uso das bromélias como planta ornamental no Brasil, segundo Anacleto e Negrelle (2009) teve início na década de 70, com grande aceitação por parte dos consumidores, em especial devido a beleza do colorido das folhas e também pela durabilidade das flores, sendo que o comércio deste grupo de plantas já chegou a ocupar a oitava posição no volume de receita e venda entre as espécies ornamentais brasileiras.

O comercio de bromélias a partir da década de noventa apresentou declínio em várias regiões brasileiras inicialmente pela associação parcialmente equivocada da reprodução do mosquito da dengue nas bromélias, dado que o mosquito não tem como vetor preferencial esse grupo de plantas (NEGRELLE et al., 2012; ANACLETO; NEGRELLE, 2013)

A mudança de cenário do agronegócio bromélias no Brasil, ocorreu mais fortemente no no Paraná do que em outros Estados brasileiros. O Paraná já foi destaque no cenário nacional de produção de bromélias, ocupando a terceira maior produção no Brasil com 250 mil plantas ao ano produzidas por 144 produtores em 32 municípios (NEGRELLE; ANACLETO, 2012; ANACLETO; NEGRELLE, 2013), e tem sido apontado como responsável por apenas 3,7\% da produção nacional de bromélias, entretanto, o consumo deste recurso ornamental tem sido cotado em 9,7\% da produção brasileira (FARIA, 2005; ANACLETO; NEGRELLE, 2015). 
Dentre as regiões paranaense, o litoral do Estado era a maior região produtora englobando 100 famílias, porém, dados recentes sugerem que, somente nesta região, a redução do número de produtores foi superior a $90 \%$. Atualmente, o consumo de bromélias ornamentais no Paraná continua elevado, e a produção estadual tem se mostrado incipiente para atender a demanda muito provavelmente por problemas nos processos produtivos. (NEGRELLE; ANACLETO; 2012; ANACLETO; NEGRELLE, 2013).

A demanda por espécies exóticas e diferentes das tradicionalmente encontradas no mercado apresenta significativo e crescente valor de mercado, se enquadra nesta condição um elevado número de espécies nativas de bromélias encontradas nas florestas no Paraná e a exploração deste potencial pode promover o desenvolvimento da cadeia produtiva (ANACLETO; NEGRELLE, 2015).

Anacleto (2016) descreve que a produção de flores em geral, deve ser orientada para o consumo, ou seja, o produtor deve conhecer os desejos e necessidades dos consumidores no sentido de se atender essas premissas e assim inserir mais facilmente a produção no mercado, e fortalecendo de forma generalizada a cadeia produtiva. Apesar da relevância das bromélias no contexto do litoral do Paraná, os estudos que promovem uma análise cuidadosa do que quer e, o que pensa o consumidor de bromélias são esparsos.

A região litorânea do Paraná é rica em espécies ornamentais nativas, e a comercialização destas espécies é favorecida devido a características como a beleza, a tonalidades de cores, formatos das flores e durabilidade após a colheita no entanto Anacleto et al. (2014) sugere que entre os gargalos existentes ao desenvolvimento da atividade, merece destaque as esferas comerciais varejistas que não valorizam a comercialização da produção local, e impõe a produção regional preços abaixo do praticado em outras regiões, o que conjumina no enfraquecimento do tecido social rural, sendo necessário a reversão deste ciclo através da construção de um diálogo entre consumidores, varejistas e produtores de bromélias.

A cadeia produtiva envolve como um conjunto de atividades e uma sucessão de operações de transformação, capazes de ser separadas entre produtores, atacadistas e comerciantes, mas ao mesmo tempo interligadas, com a finalidade de atender de forma satisfatória ao consumidor final (ANACLETO, 2016).

$O$ atendimento satisfatório do consumidor, segundo Blackwell et al. (2006) é o que sustenta as relações comerciais sobre interesses comuns e complementares de cada segmento dentro da cadeia produtiva, que dependem um do outro para sua eficiência, assim o ambiente colaborativo deve ser adequadamente articulado, no sentido de pensar o conjunto, e em um modelo de atuação de governança que beneficie todos os segmentos.

O comercio varejista dentro da cadeia produtiva, tradicionalmente promove a ligação entre os produtores e atacadistas ao consumidor final, e neste contexto, é o principal facilitador no melhor entendimento das condições de comércio de flores e no diagnóstico das inadequações comerciais que podem desestimular os consumidores finais.

Segundo Muraro et al. (2016) o comercio varejista deve dentro da cadeia produtiva alimentar o sistema de produção dos problemas relatados pelos consumidores e dos possíveis fatores que podem reduzir o consumo ou favorecer 
a migração do consumo para os produtos substitutos, assim se torna essencial o diálogo entre varejistas e consumidores finais e a apresentação do que quer e deseja os consumidores aos produtores rurais.

A principal ferramenta metodológica que pode monitorar os anseios do cliente para a fidelização do produto segundo Kotler e Keller (2012) é a avaliação do composto mercadológico de marketing, popularmente conhecido como os $4 \mathrm{P}^{\prime}$ s revela a forma de abordar uma especificidade e, consegue alcançar mais eficazmente seu público alvo.

Os 4P's segundo Kotler e Keller (2012) são divididos em fatores que podem impactar o comércio de determinado produto, em preço, praça, promoção e produto, neste contexto a avaliação permite identificar os nichos de mercado se posicionando no desenvolvimento de estratégias voltadas especificadamente a fidelização a este público, Segundo Anacleto (2016) também é possível identificar os fatores de descontentamentos e repassar a informação aos produtores rurais para que esses fatores possam ser corrigidos nas próximas safras, bem como para que se possa atingir novas classes de consumidor e ampliar os níveis de crescimento do mercado.

Assim, com o intuito de subsidiar o melhor entendimento da produção e comercio de bromélias no litoral paranaense com base na avaliação do composto mercadológico (4Ps), realizou-se estudo que objetivou promover um diagnóstico sobre o perfil e comportamento do consumidor de bromélias no litoral do Paraná, e buscou responder especificamente as seguintes questões:

a) Promover um diagnóstico relativo às médias de consumo e a caracterização socioeconômica do consumidor bromélias no litoral do Paraná.

b) Identificar os motivos principais que podem dificultar o consumo de bromélias em relação ao mercado varejista.

c) Identificar os motivos principais que podem dificultar o consumo de bromélias em relação ao produto como forma de orientar a produção no campo.

d) Investigar se o comportamento do consumidor é alterado em função da classe econômica, escolaridade, renda ou gênero.

\section{MATERIAL E MÉTODOS}

A pesquisa desenvolvida neste estudo pode ser caracterizada como exploratória-descritiva, e foi realizada entre julho de 2016 a fevereiro de 2017, a partir de entrevistas presenciais (SCHIMMENTI et al., 2013).

A amostra populacional foi de 120 consumidores de bromélias, e atendeu as orientações de pesquisa de marketing e perfil de consumo quando a população é desconhecida (MALHOTRA, 2010), sendo que de acordo com o proposto por Anacleto et al. (2014) exigia que o consumidor tivesse comprado Bromélias pelo menos uma vez nos últimos doze meses, e que apresentasse concordância em participar da pesquisa não identificada.

Adotou-se a distribuição etária conforme IBGE (2016) e a classificação da condição econômica de acordo com o Critério Brasil de (ABEP, 2016). 
A análise dos dados identificou a existência de correlação entre consumo anual de a classe investigada em relação a gênero, escolaridade, renda, idade e estado civil, sendo que as variáveis qualitativas foram caracterizadas através de frequências absolutas e relativas (\%) e as variáveis quantitativas através da média e desvio-padrão (MALHOTRA, 2010; ANACLETO et al., 2014).

De acordo com o proposto por Anacleto et al. (2015) a normalidade dos dados foi avaliada com o Teste de Kolmogorov-Smirnov. Os resultados do teste ( $p$ $<0,05)$ levaram a rejeitar a normalidade das variáveis avaliadas número de compra de Bromélias para uso e para presentear, levando à decisão de utilizar testes não paramétricos.

A avaliação da influência de gênero, idade, escolaridade e condição econômica sobre níveis de consumo de Bromélias foi avaliada de acordo com o proposto por Anacleto et al. (2014). Para tanto, aplicou-se testes não paramétricos de Mann-Whitney e Kruskal-Wallis, seguido do teste de comparação múltipla das médias de Dunn, em nível de significância de 5\% ( $p<$ $0,05)$, para a identificação dos pares de grupos com diferenças estatisticamente significativas (HAIR et al. 2009).

A comparação das variáveis (comparação entre Bromélias para uso e para presentear) foi realizada com o teste de Wilcoxon para amostras pareadas, sendo considerado um nível de significância de 5\% $(p<0,05)$ (HAIR et al. 2009),

O comportamento de compras do consumidor de Bromélias foi constituído a partir das informações coletadas relativas a frequência de compras, motivos da compra e as Bromélias preferenciais (MALHOTRA, 2010).

A mensuração das espécies mais importantes, os fatores que limitavam a ampliação do consumo de Bromélias, períodos de maior consumo, espécies mais consumidas entre foram obtidas através da categorização hierárquica que permitia a cada entrevistado emitir três indicações por categoria.

O composto de marketing foi avaliado acordo com o proposto por Anacleto et al. (2015) com o uso de escala em que o entrevistado atribuía notas de 0 a 10, sendo que notas médias menores que 6,9 indicariam insatisfação. As notas médias igual a 7 identificariam nulidade, e as notas médias igual ou superior a 7,1 indicariam satisfação com o item do composto de marketing referente a compra de Bromélias.

\section{RESULTADOS}

A compras de bromélias entre os entrevistados foi em média de 3,62 vezes ano ${ }^{-1}$, e a maioria dos consumidores de Bromélias eram mulheres (80\%), o estudo mostra que existiam diferenças significativas na quantidade de Bromélias comprada entre homens e mulheres quanto ao número compras para uso ( $p=$ $0,324)$, porém não haviam diferenças significativas quanto ao número de compras de bromélias entre os gêneros quando o motivo era presentear (Tabela 1). 
Tabela 1 - Comparação entre o número de vezes que os consumidores compraram bromélias para uso e para presentear, nos últimos 12 meses, por gênero $(n=120)$

\begin{tabular}{|c|c|c|c|c|}
\hline \multirow{2}{*}{ Gênero } & \multicolumn{2}{|c|}{ Para uso } & \multicolumn{2}{|c|}{ Para presentear } \\
\hline & Média & $\begin{array}{l}\text { Desvio- } \\
\text { padrão }\end{array}$ & Média & $\begin{array}{l}\text { Desvio- } \\
\text { padrão }\end{array}$ \\
\hline Feminino $(n=96)$ & $3,83 \mathrm{a}$ & 2,64 & $1,36 \mathrm{a}$ & 0,52 \\
\hline Masculino $(n=24)$ & $1,01 \mathrm{~b}$ & 0,85 & 1,19 a & 0,53 \\
\hline Teste de Mann-Whitney & \multicolumn{2}{|c|}{$p=0,324$} & \multicolumn{2}{|c|}{$p=0,422$} \\
\hline
\end{tabular}

$p$ - valor de significância do Teste de Mann-Whitney.

As médias de consumo de bromélias em relação ao estado civil foram não apresentaram diferenças significativas no consumo, nem para uso próprio, nem para presentear (Tabela 2).

Tabela 2 - Comparação entre o número de vezes que os consumidores compraram flores para uso e para presentear, nos últimos 12 meses, por estado civil $(\mathrm{N}=120)$

\begin{tabular}{|c|c|c|c|c|}
\hline \multirow{2}{*}{ Gênero } & \multicolumn{2}{|c|}{ Para uso } & \multicolumn{2}{|c|}{ Para presentear } \\
\hline & Média & $\begin{array}{l}\text { Desvio- } \\
\text { padrão }\end{array}$ & Média & $\begin{array}{l}\text { Desvio- } \\
\text { padrão }\end{array}$ \\
\hline Solteiro $(n=20)$ & $1,28 \mathrm{a}$ & 1,67 & $1,61 \mathrm{a}$ & 0,93 \\
\hline Casado $(\mathrm{n}=86)$ & $1,83 \mathrm{a}$ & 1,71 & $1,64 \mathrm{a}$ & 1,20 \\
\hline Divorciado $(n=11)$ & $1,00 \mathrm{a}$ & 0,93 & $1,66 \mathrm{a}$ & 0,91 \\
\hline Viúvo $(n=3)$ & $1,28 \mathrm{a}$ & 1,20 & $1,37 \mathrm{a}$ & 0,71 \\
\hline Teste de Kruskal-Wallis & \multicolumn{2}{|c|}{$p=0,321$} & \multicolumn{2}{|c|}{$p=0,912$} \\
\hline
\end{tabular}

$p$ - valor de significância do Teste de Kruskal-Wallis.

O estudo revelou que a medida que se eleva a escolaridade, se eleva também a média de aquisições de bromélias para consumo, assim como para presentear (Tabela 3) 
Tabela 3 - Comparação entre o número de vezes que os consumidores compraram flores para uso e para presentear, nos últimos 12 meses, por grau de escolaridade $(N=120)$

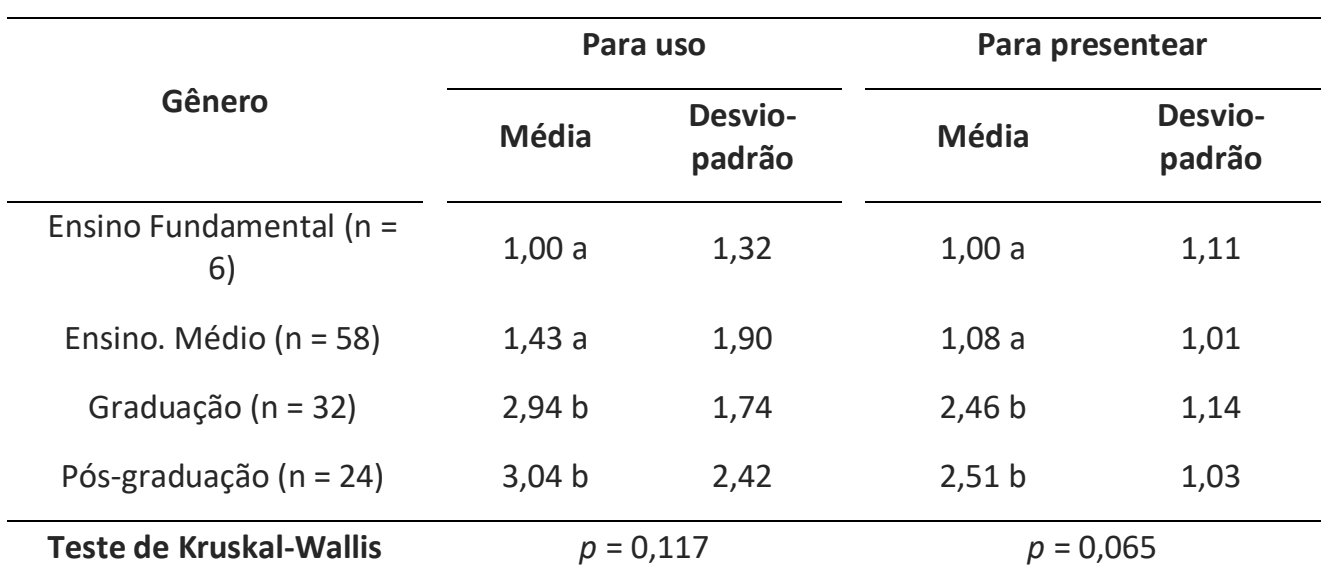

A idade não é um fator decisório no consumo de bromélias no número aquisições para uso ou para presentear (Tabela 4).

Tabela 4 - Comparação entre o número de vezes que os consumidores compraram bromélias para uso e para presentear, nos últimos 12 meses, por grau faixa etária ( $\mathrm{N}=$ 120)

\begin{tabular}{|c|c|c|c|c|}
\hline \multirow[b]{2}{*}{ Gênero } & \multicolumn{2}{|c|}{ Para uso } & \multicolumn{2}{|c|}{ Para presentear } \\
\hline & Média & $\begin{array}{l}\text { Desvio- } \\
\text { padrão }\end{array}$ & Média & $\begin{array}{l}\text { Desvio- } \\
\text { padrão }\end{array}$ \\
\hline$<20$ anos $(n=5)$ & $2,10 a$ & 1,11 & $1,35 \mathrm{a}$ & 0,95 \\
\hline $20-29$ anos $(n=21)$ & $1,67 \mathrm{a}$ & 1,74 & $1,46 \mathrm{a}$ & 0,76 \\
\hline $30-39$ anos $(n=27)$ & $1,38 \mathrm{a}$ & 1,77 & $1,83 \mathrm{a}$ & 1,10 \\
\hline $40-49$ anos $(n=33)$ & $1,95 \mathrm{a}$ & 1,52 & $1,66 \mathrm{a}$ & 1,00 \\
\hline $50-59$ anos $(n=15)$ & $1,99 \mathrm{a}$ & 2,22 & $1,59 \mathrm{a}$ & 1,37 \\
\hline $60-69$ anos $(n=13)$ & $3,11 \mathrm{a}$ & 3,01 & $1,88 \mathrm{a}$ & 1,50 \\
\hline$\geq 70$ anos $(n=6)$ & $1,40 \mathrm{a}$ & 1,20 & $1,75 \mathrm{a}$ & 0,69 \\
\hline Teste de Kruskal-Wallis & \multicolumn{2}{|c|}{$p=0,167$} & \multicolumn{2}{|c|}{$p=0,612$} \\
\hline
\end{tabular}

$p$ - valor de significância do Teste de Kruskal-Wallis.

A renda familiar mensal pode ser classificada como fator decisivo no consumo de bromélias, observou-se diferenças significativas nas compras para uso assim como na compra das flores para presentear (Tabela 5). 
Tabela 5 - Comparação entre o número de vezes que os consumidores compraram flores para uso e para presentear, nos últimos 12 meses, por grau de renda familiar mensal ( $\mathrm{N}=$ 120)

\begin{tabular}{|c|c|c|c|c|}
\hline \multirow[b]{2}{*}{ Gênero } & \multicolumn{2}{|c|}{ Para uso } & \multicolumn{2}{|c|}{ Para presentear } \\
\hline & Média & $\begin{array}{l}\text { Desvio- } \\
\text { padrão }\end{array}$ & Média & $\begin{array}{l}\text { Desvio- } \\
\text { padrão }\end{array}$ \\
\hline $\begin{array}{l}\text { De } R \$ 600 \text { a } R \$ 1.349 \\
(n=00)\end{array}$ & 0,00 & 0,00 & 0,00 & 0,00 \\
\hline $\begin{array}{l}\text { De } R \$ 1.350 \text { até } \\
R \$ 2.249(n=9)\end{array}$ & $1,29 a$ & 1,03 & $1,30 a$ & 1,08 \\
\hline $\begin{array}{l}\text { De } R \$ 2.250 a \\
R \$ 3.999(n=36)\end{array}$ & $1,07 a$ & 1,33 & $1,09 a$ & 1,01 \\
\hline $\begin{array}{l}\text { De } R \$ 4.000 \text { a } R \$ \\
7.799(n=32)\end{array}$ & $3,54 b$ & 2,78 & $3,42 b$ & 2,34 \\
\hline $\begin{array}{l}\text { De R\$7.800 a } \\
R \$ 18.799(n=23)\end{array}$ & $4,05 \mathrm{~b}$ & 2,08 & $3,74 \mathrm{~b}$ & 2,06 \\
\hline $\begin{array}{l}\text { Teste de Kruskal- } \\
\text { Wallis }\end{array}$ & \multicolumn{2}{|c|}{$p=0,001$} & \multicolumn{2}{|c|}{$p=0,001$} \\
\hline
\end{tabular}

aNão existem diferenças significativas entre os grupos ( $p>0,05$ no teste de comparações múltiplas pelo procedimento de Dunn).

As espécies mais citadas pelos consumidores foram AechmeafasciataBaker, Gusmanialingulata, Vriesiaincurvata, Nidulariuminnocentii e Vriesiacarinata.

A compra de bromélias para presentear, tinha como principal motivo os aniversários,seguido pelo dia das mães que juntos representavam $85 \%$ das compras com este objetivo seguido pela compra nodia dos Namorados, dia da mulher e casamentos que juntos representavam 11\% das compras.

O estudo mostrou que em contexto geral os índices de satisfação relativos ao composto mercadológicos do comercio de bromélias não atendia os consumidores especialmente nas questões relacionadas a preço e onde comprar a flor (Tabela 6), 
Tabela 6 - Índices de satisfação do consumidor de Bromélias comercializadas no litoral do Paraná em relação ao composto de marketing na última compra (n=169).

\begin{tabular}{|c|c|c|c|}
\hline & & $\begin{array}{c}\text { Satisfação } \\
\text { pós- } \\
\text { compra }\end{array}$ & $\begin{array}{l}\text { Classificação } \\
\text { do atributo }\end{array}$ \\
\hline \multirow[t]{2}{*}{ Preço } & Preço & 5,72 & Negativo \\
\hline & Encontrar na quantidade desejada & 7,12 & Positivo \\
\hline \multirow[t]{2}{*}{ Praça } & Encontrar a espécie desejada & 6,05 & Negativo \\
\hline & $\begin{array}{l}\text { Encontrar facilmente uma } \\
\text { floricultura }\end{array}$ & 6,00 & Negativo \\
\hline \multirow[t]{5}{*}{ Promoções } & Promoções & 5,71 & Negativo \\
\hline & Aparência das Bromélias & 7,85 & Positivo \\
\hline & Padronização das Bromélias & 7,40 & Positivo \\
\hline & Colorido das Bromélias & 8,20 & positivo \\
\hline & Qualidade do atendimento & 6,03 & Negativo \\
\hline
\end{tabular}

*Média 7 identifica nulidade; média 7,1ou mais indica satisfação; média menor que 6,9 indica insatisfação

\section{DISCUSSÃO}

Os resultados apontados no presente estudo, revelam que o perfil sócio econômico do consumidor de bromélias no litoral do Paraná são similarmente ao descrito por Anacleto et al. (2014) em sua maioria por de pessoas do gênero feminino, com elevado nível de escolaridade, também possuem maior poder aquisitivo.

A compra média por ano foi de 3,62 vezes, sendo mulheres, que apresentaram o dobro do consumo em relação aos homens, quando a compra era efetuada para consumo próprio. A provável explicação para essa diferença no consumo, pode estar residindo nas questões culturais, dado que segundo Kotler (1998) pode ser classificado como um dos fatores mais fundamentais na relação de desejos e do comportamento de uma pessoa. Similarmente ao percebido no consumo de flores, conforme relatado por Junqueira e Peetz (2014), Anacleto et al. (2014) Anacleto et al (2015) e Sebrae (2015) onde as mulheres para outras espécies também são as maiores consumidoras, o comportamento pode estar atrelado as crenças e costumes aprendidos com as mais velhas, o que comumente acabam adquirindo um conjunto de valores, percepções, preferências e comportamento através da vida em família, a cultura é portanto a herança social nas relações humanas e pode ser aprendida de forma dinâmica, este fato pode ser evidenciado em outras espécies de flores (JUNQUEIRA; PEETZ, 2014; ANACLETO et al., 2014; ANACLETO et al., 2015; SEBRAE, 2015) e pode estar refletindo também no consumo de bromélias.

O perfil do consumidor de bromélias também é similar a outras espécies de flores (JUNQUEIRA; PEETZ, 2014) no que tange a renda e escolaridade. De acordo com Kotler (1998), os hábitos de compra das pessoas variam durante sua vida, sendo que o gosto das pessoas pode estar relacionado pelo estágio do ciclo de 
vida da família, onde a escolaridade e renda são fatores de influencias diretas. A escolaridade afeta o indivíduo pelo contado com a informação e o conhecimento de novos modelos de consumo, além do que maiores níveis de escolaridade em contexto geral resultam em maiores níveis de renda o que favorece o consumo. Desta forma a renda está associada na maioria das vezes com a ocupaçãoe a profissão que o consumidor exerce, assim a atividade remunerada de uma pessoa influencia seus padrões de consumo.

O consumo em relação aos 4Ps era favorecido pelo atendimento dos desejos dos consumidores em relação ao Produto, cujos índices de satisfação se mostraram elevados no quesito beleza da planta, na facilidade de encontrar a bromélia para comprar, a padronização das espécies e a variedade de cores.

Os consumidores quando buscam um produto para comprar formam mentalmente uma expectativa sobre a qualidade deste produto. As expectativas são baseadas nas necessidades e desejos dos indivíduos, nas suas experiências pessoais do passado, e na influência de terceiros, sendo que após o consumo, o consumidor promove um comparativo entre o que ele desejava e o que realmente obteve após a compra, se o desempenho ficar acima das expectativas, - consumidor estará altamente satisfeito ou encantado, o que leva a possibilidade de um novo consumo, como o observado em relação ao produto bromélias.

Atender os desejos dos consumidores em relação ao produto, se constitui em um importante fator na fidelização do consumo de um produto, Kotler (1998) descreve que a satisfação dos desejos do consumidor pode ser compreendida como o sentimento de prazer ou de desapontamento resultante da comparação do desempenho esperado pelo produto (ou resultado) em relação às expectativas da pessoa.

Uma vez que o produto cumpre o proposto no que se refere ao atendimento dos desejos dos clientes, é necessário a análise sobre os fatores que podem dificultar o consumo bromélias.

O estudo revelou que entre os fatores negativos identificados pelos consumidores a dificuldade de encontrar a espécie desejada nos locais de compra, a ausência de promoções, o atendimento no momento da compra, e especialmente o preço do produto classificado como elevado foram classificados como negativos.

Observou-se que em relação a espécie desejada os consumidores relataram dificuldades em se obter a prioridade na escolha, sob esse aspecto Anacleto et al. (2014) relata que a partir do momento que o cliente não consegue obter a espécie desejada, ele busca outras opções na satisfação dos seus desejos, especificamente no que se concerne as bromélias, os produtos substitutos podem ser as outras flores ou ainda chocolates, bebidas e roupas.

Assim, identificar qual espécie que é objeto de desejo do cliente, e inserir no canal de distribuição do produto deve ser deve premissa ao mercado, que deve observar quais são as tendências e preferencias do cliente em relação ao produto. O mais importante é o canal comercial se atentar e buscar obter informações atualizadas sobre seu produto, pois é fundamental para qualquer segmento se manter flexível no mercado. Desta forma, a produção no campo deve ser orientada no sentido de se priorizar as espécies mais procuradas pelos 
consumidores que devem estar presentes nas prateleiras dos varejistas, tornando o consumo mais fácil e reduzindo a ação dos produtos substitutos.

O principal fator que afeta o comportamento do consumidor de bromélias no litoral do paraná, similarmente ao relatado para outras espécies de flores é a questão preço.

A exceção em consumidores de elevados padrão aquisitivo, o preço elevado é o principal fator que altera o comportamento do consumidor, segundo Blackwell et al. (2006) quando o preço é classificado como elevado, a primeira reação do consumidor é a busca por um produto que substitua e que tenha finalidade similar, a compra de bromélias quando para presentear se torna ainda mais susceptível a essa questão, devido a vasta gama de produtos ofertados no mercado com preços menores, bem como a existência de outras flores com menores preços nos próprios estabelecimentos varejistas, Anacleto et al. (2014) ressalta que alternativa a questão preço a oferta de promoções poderia ser um atenuante, porem segundo o autor dado a sistemática deste comercio varejista, as promoções não são práticas recorrentes e possivelmente são adotadas apenas em grandes estabelecimentos. Assim surge quando não é possível, a redução de preços como alternativa a ampliação do consumo, surge o marketing de relacionamento na redução deste impacto.

O principal fator no marketing de relacionamento como medida de fidelizar o consumo está na qualidade de atendimento, se identificado pelo consumidor, o mau atendimento, não deve ser ignorado, pois é através deste canal que o consumidor define se efetivara a sua compra. Desta forma o atendente deve ser prestativo, possuir conhecimento do produto que está sendo comercializado, para sanar as possíveis dúvidas dos clientes e deve estar atento a sugestões e aos gostos do consumidor, para repassá-las ao gestor do negócio, que por sua vez deve repassar as informações no sentido de orientar a produção no campo.

$\mathrm{O}$ atendimento pós-venda pode se tornar uma ferramenta muito eficiente para o canal, folhetos ilustrativos de como proceder com a manutenção correta do produto, ocasionalmente, avisar o consumidor quando o produto estiver disponível para as vendas, registrar a preferência do cliente, para que este perceba que é importante para a empresa e outro fator importante, é a especialização do colaborador. A busca por melhorias no negócio, independente da segmentação é essencial, pois demonstra confiança ao consumidor, agrega valor ao produto, o preço deixa de se tornar um fator negativo, pois existe qualidade no atendimento, que já não é mais um diferencial, e sim uma exigência para a garantir a sobrevivência da empresa no mercado.

O composto mercadológico de vendas está associado a cada produto disponibilizado ao mercado e as diferentes formas de satisfazer o conjunto de necessidades dos clientes (KOTLER, KELLER, 2012), especificamente no comercio de flores e plantas ornamentais, para que esta relação seja instalada e a satisfação da necessidade seja percebida, é necessário criar as condições favoráveis que atraia o consumidor.

O marketing de relacionamento busca de envolver o cliente nas decisões de comercio da empresa, fazendo com que os mesmos possam participar com orientações de melhores produtos, principalmente possibilitando avaliações dos os anseios do consumidor ao produtor de flores que por sua vez promove as 
correções do produto, o que pode satisfazer ao consumidor que mantem-se fiel ao consumo, o que também pereniza ao comercio varejista e reduz drasticamente a influência dos produtos substitutos.

As ações de marketing de relacionamento podem viabilizar a fidelidade dos clientes, o que segundo Blackwell et al. (2006) o varejista deve priorizar a retenção dos atuais clientes em função de um custo menor para manter os clientes em relação à conquista de novos.

Desta forma, de acordo com Blackwell et al. (2006) e Kotler e Keller (2012) o marketing de relacionamento desenvolve atividades destinados a desenvolver ligações economicamente eficazes de longo prazo entre uma organização e seus clientes para o benefício mútuo de ambas as partes criando um ciclo virtuoso entre produtores de bromélias, varejistas de flores e produtores rurais.

\section{CONSIDERAÇÕES FINAIS}

Identificou-se o gênero feminino como consumidor majoritário $(n=80)$, que efetuavam em média 3,62 compras por ano, sendo que idade e estado civil não se configuram como fatores decisivos ao consumo. Fo identificado que as bromélias possuem significante aprovação do consumo no que se refere a beleza das flores, padronização das plantas e colorido das plantas

Os principais motivos que podem dificultar um consumidor a consumir bromélias em relação ao mercado varejista é o preço classificado como elevado e a ausência de promoções que facilitem a aquisição do produto.

Os produtores de bromélias no campo necessitam ampliar o leque de espécies produzidas dado que os consumidores relataram insatisfação no sentido de que poucos tipos de bromélias diferentes são ofertados nas lojas.

Os principais fatores que podem alterar o consumo de bromélias estão associados a renda e escolaridade, portanto ações de marketing de relacionamento direcionado a esse público especifico pode promover a fidelização dos consumidores.

A orientação dos varejistas aos produtores pode criar um ambiente colaborativo ampliando a eficiência da produção no campo, e dos níveis de satisfação do consumo, fortalecendo a cadeia produtiva de bromélias no litoral do Paraná. 


\title{
Bromélias consumer profile and behavior: rural production orientation
}

\begin{abstract}
Bromeliads on the coast of Paraná have commercial exploitation associated with socially vulnerable communities, but little is known about the desires of consumers, in this context, we present the result of the evaluation on the influence of the marketing compound on consumer behavior of bromeliads, aiming to subsidize the establishment of actions in the field to strengthen the productive chain. In order to achieve the objectives, an exploratory-descriptive study was carried out between July 2016 and February 2017, with 150 bromeliad consumers. The female gender was identified as the majority consumer $(n=80)$, who made an average of 3.62 purchases per year, with a tendency to increase consumption, as schooling and income advanced. The study also showed that although the consumer is satisfied with the bromeliads as ornamental plants the expectation is not met especially in relation to the price classified as high. It is concluded that the forms of production in the field should be re-evaluated, the number of species prioritizing the most desired by the customers. The orientation of the retailers to the producers can create a collaborative environment, increasing the efficiency of the production in the field, and the levels of satisfaction of the consumption, strengthening the productive chain of bromeliads in the coast of Paraná.
\end{abstract}

KEY WORDS:Trade in flowers, agribusiness, ornamental plants, floriculture, coast of Paraná. 


\section{REFERÊNCIAS}

ABEP - ASSOCIAÇÃO BRASILEIRA DE EMPRESAS DE PESQUISA. Critério de Classificação Econômica Brasil. Disponível em: $<w w w$.abep.org $>$. Acesso em 26 de novembro 2016.

ANACLETO, A. Flowerssupplychain in Paraná Coast-Brazil: anapplicationof Miles andSnowtaxonomy. Revista Capital Científico, v. 14, n. 1, p. 10-25, 2016.

ANACLETO, A., FUJITA, E. S., MENDES, L. P., MACENO, R. Influenceofthe 4Ps in theBuyingBehaviorofElderlyConsumersFlowers in Paraná Coast-Brazil. InternationalJournalofEngineeringResearch \& Science, v.1, n. 9, p. 119-125, 2015.

ANACLETO, A.; NEGRELLE, R. R. B. Comércio de bromélias no Paraná. Revista Ceres, v. 60, n. 2, p. 185-193, 2013.

ANACLETO, A.; NEGRELLE, R. R. B. Viabilidade econômica do cultivo de bromélias. Revista Capital Científico, v. 13, n. 2, p. 75-95, 2015.

ANACLETO, A.; NEGRELLE, R. R. B. KOEHLER, H. S. GerminationofAechmeanudicaulis (L.) Griseb.(Bromeliaceae) in differentsubstracts as alternativestoDicksoniasellowianaHook. Acta Scientiarum. Agronomy, v. 30, n. 1, p. 73-79, 2008.

ANACLETO, A.; NEGRELLE, R. R. B. Extrativismo de rametes e propagação vegetativa de Aechmeanudicaulis (L.) Griseb.(Bromeliaceae). Scientia Agraria, v. 10, n. 1, p. 85-88, 2009.

ANACLETO, A. NEGRELLE, R. R.B, MURARO, D. TOYOFUKO, T. M. Profile andbehaviorofthebromeliadsconsumer in Paraná State - Brazil. Business Management Review, v. 5, n. 1, p.12-19, 2014.

BLACKWELL R.D.; ENGEL JF; MINIARD P.W ConsumerBehavior.10ª ed. Ohio: South Wester, 2006, 832p.

FARIA, R. T. Floricultura: as plantas ornamentais como agronegócio. Londrina: Mecenas, 103 p. 2005.

HAIR, JR., J.F.; ANDERSON, R.E.; TATHAM, R.L., BLACK, W.C. Análise multivariada 
IBGE - Livro Estudos \& Pesquisas: Informação Demográfica e Socioeconômica 32, Síntese de Indicadores Sociais - Uma Análise de Vida da População Brasileira (2013)http://biblioteca.ibge.gov.br/visualizacao/livros/liv66777.pdfAcessado em 10/01/2016

JUNQUEIRA, A. H.; PEETZ, M. S. O Setor Produtivo de Flores e Plantas Ornamentais do Brasil, no Período de 2008 a 2013: Atualizações, Balanços E Perspectivas. Revista Brasileira de Horticultura Ornamental, Campinas, vol. 20, n. 2, p.115-120, 2014.

KOTLER, P. Administração de marketing: analise planejamento, implementação e controle. 5 ed. São Paulo: Atlas, 1998.

KOTLER, P.; KELLER, K. Marketing Management, Upper Saddle River, New Jersey: Prentice-Hall, 2012. 816p.

MALHOTRA, N K. Marketing research: An applied orientation. Upper Saddle River, New Jersey: Pearson, 2010.

MURARO, D.; ANACLETO, A.; NEGRELLE, R. R. B. et al. Market management: the impact on the development of an ornamental plants supply chain in Curitiba, Brazil. Ciencia e Investigación Agraria, v. 42, n. 3, p. 453-460, 2016.

NEGRELLE, R. R.B. MITCHELL, D.; ANACLETO, A. Bromeliad ornamental species: conservationissues and challengesrelated to commercialization. Acta Scientiarum. BiologicalSciences, v. 34, n. 1, 2012.

SEBRAE, Flores e Plantas Ornamentais do Brasil. Brasília: Sebrae, vol. 1 n.1, 42p. 2015.

SCHIMMENTI, E.; GALATI, A.; BORSELLINO, V.; IEVOLI, C.; LUPI, C.; TINERVIA, S.. Behaviour of consumers of conventional and organic flowers and ornamental plants in Italy. Horticultural Science, v. 40, n. 4, p. 162-171, 2013. 
Recebido: 29 ago. 2017

Aprovado: 19 out. 2017

DOI: $10.3895 /$ rbpd.v7n1.7055

Como citar: ANACLETO, A.; BORNACIN, A. P. A. Perfil e comportamento do consumidor de bromélias:

orientação a produção rural. R. bras. Planej. Desenv.,Curitiba v. 7, n. 1, p. 51-66, jan./abr. 2018. Disponível

em: <https://periodicos.utfpr.edu.br/rbpd>. Acesso em: XXX.

Correspondência:

Adilson Anacleto

Av, Universitária 1.440, Setor Universitário, Goiânia, Goiás, Brasil

Direito autoral: Este artigo está licenciado sob os termos da Licença CreativeCommons-Atribuição 4.0

Internacional.

$$
\text { (c) (1) }
$$

